Behavior and Social Issues, 18, 10-14 (2009). (C) João Claudio Todorov. Readers of this article may copy it without the copyright owner's permission, if the author and publisher are

acknowledged in the copy and the copy is used for educational, not-for-profit purposes.

\title{
BeHAVIORAL ANALYSis Of Non-ExPERIMENTAL DATA Associated With Cultural Practices
}

\author{
João Claudio Todorov \\ Instituto de Educação Superior de Brasília (IESB)
}

\begin{abstract}
Behavior analysis is usually seen as the experimental analysis of individual behavior, a distinctive contribution of the field to psychology in general. But what characterizes behavior analysis since Skinner's days is the scientific method, not only experimentation, and not exclusively individual behavior. Behavior analysis as science may use field observation, for instance. Prediction and confirmation or disconfirmation do not require experimentation. The present work discusses some examples of behavior analyses of cultural practices in which the observation of interlocked behavior contingencies may happen without experimentation.
\end{abstract}

KEYWORDS: scientific method, behavior analysis, metacontingencies, interlocking behavioral contingencies

Behavior analysis is often referred to as the experimental analysis of behavior, a method, an area, a philosophy, a technology (e.g., the ABA method for treating autism). The prevalence of the part over the whole probably is due to an overemphasis on experiments. A behavior analyst is supposed to manipulate some independent variable, carefully observing its effect on some very closely observed measure of behavior.

The experimental analysis of individual behavior has been the trademark of behavior analysis, whether in basic research or applied work. However, behavior analysis is more than experimental analysis. Skinner (1953), writing on behavior analysis of human behavior, was clear on that point. Paraphrasing Skinner, one could say that behavior analysis is first of all a set of dispositions. It is a disposition to deal with behavior rather than with what someone has said about behavior. Behavior analysis is a willingness to accept facts about behavior even when they are opposed to wishes. Behavior analysts have also discovered the value of remaining without an answer until a satisfactory one can be found. Behavior analysis is a search for order, for uniformities, for lawful relations among environment and behavior (Skinner, 1953, pp. 12-13).

The material to be analyzed in a science of behavior comes from many sources: casual observations, controlled field observations, clinical observation, extensive observation under rigidly controlled conditions in institutional research, 
and laboratory studies of human behavior (Skinner, 1953, p. 37). The behavior of a single subject can be observed under many circumstances, even when other individuals are present. When the focus of interest is individual behavior, a social episode can be described using the same terms, concepts and principles involved in the interaction of a person with his physical environment. Groups do not behave, but the behavior of persons in groups has been of interest to behavior analysis. While groups do not behave, the behavior of persons grouped together produces unique results.

When working with social issues, the focus on a single subject can be expanded to the analysis of cultural practices involving groups of persons behaving in concert, where the behavior of a person has sense only when considered in the context of the result of the group. One way to study cultural practices is to analyze large sets of data that are gathered by private or public organizations. Another way to study cultural practices is the use of systematic observation of groups engaging in such practices.

Cultural practices often involve interlocking behavioral contingencies, where the behavior of one person may provide positive consequences for the behavior of a second person, discriminative stimuli for the behavior of a third person, and so on. In that case a cultural practice is structured through those interlocking behavioral contingencies (IBCs), which produce an aggregate product (a folk dance, for example), maintained by cultural consequences. Such practices usually are learned within the socialization process of the young and/or through the educational system. The relation between cultural consequences and a set of IBCs can be summarized as follows: If an IBC set produces an aggregate product, then the social environment reacts with cultural consequences. Successive changes in the selection criterion may result in changes in the IBC set. When there is no planning involved in those criterion changes, behavior contingencies may survive within an IBC even without a function regarding the aggregate product.

Cultural consequences may be aversive, and in that case the aggregate product may be positive for a group of persons (e.g., bandits in a gang) and negative for others (society in general); the gang's IBCs will survive whenever aversive consequences are avoided. Sets of IBCs may compete for cultural consequences coming from the same selecting source, as in a competition of college bands.

\section{Legal CONTROL}

Non-experimental studies of cultural practices being formed or transformed were conducted by Todorov, Moreira, Prudêncio \& Pereira (2004), Machado \& Todorov (2008), and Silva \& Todorov (2008). Todorov et al. (2004) analyzed the 
text of the Brazilian law designed to protect children and adolescents and examined the official records of the judiciary system dealing with children and adolescents in Brasília, Brazil. As described by Todorov (2005), legal control involves a web of laws. A single unlawful act puts an entire apparatus in motion. In Brazilian law, children and adolescents do not perform unlawful acts; at most, their behavior may be in conflict with the law. Thus the law introduces a new vocabulary, which should be accompanied by new cultural practices regarding children and adolescents.

The analysis of laws as metacontingencies, as sets of interlocked individual contingencies, helps in the study of how, when, and why laws do control behavior. Laws are made of three-term contingencies, interlocked in metacontingencies. Thus, one way of looking at how a law controls behavior is to begin with the analysis of the law as a written statement of interlocked contingencies that control individual behavior

The law is better written when it deals with undesirable behavior of adolescents and the desirable behavior of governmental agents when dealing with that undesirable behavior. With other issues, however, the law is not clear. An incomplete contingency opens the possibility of different interpretations, and sometimes inaction. Article 4 of the law stipulates that it is the duty of the family, the local community, society in general and the government to assure the rights of children to food and health, without specification of consequences. As a way to control behavior, this is as good as nothing. In a judiciary system that is already slow, decision making by judges and attorneys sometimes follows the line of least effort. Police brutality, even with children, is seen in some parts of the country as a necessary educational measure (Todorov et al., 2004; Todorov, 2005).

In other cases the protection measures determined by the law are costly in terms of resources and manpower, so nothing happens. Thus, for a technological metacontingency to produce new cultural practices, other agencies besides the judiciary must act, like the educational system and nowadays the media, especially television, with the society as a whole acting as external control of governmental agencies.

\section{Prediction ANd CONFIRMATion}

The analysis of cultural phenomena and associated cultural practices may use any method which may lead to prediction and confirmation or disconfirmation. Silva \& Todorov (2008) examined the records from 1998 to 2006 of a labor cooperative in Goiânia, State of Goiás, Brazil, interviewed members of the cooperative, and observed their operation in the present. Being a reunion of poor workers with a very low socioeconomic and educational level, the cooperative 
began mostly controlled by the rules of the Brazilian law regarding labor cooperatives, with the help of university students and teachers. The cooperative worked with recyclable material from garbage dumps, producing plastic pellets to sell to hose factories, and tiles made of paper, made waterproof through a chemical treatment. By law, a cooperative is run by its general assembly. Silva \& Todorov (2008) found that at the beginning, in 1998, assembly meetings were frequent and the number of issues discussed was large, as expected from rulegoverned behavior controlled by the text of the law. As the work advanced the number of meetings decreased, the assembly delegated power to councils, and later to managers. Issues discussed were few and directly related to production and sales. The cooperative was being run mostly like a small business, under the control of the market rather than rules; it had been transformed into a business like any other by direct exposition to contingencies.

\section{NATURAL EXPERIMENTS}

Major changes in cultural practices are happening everyday in some part of the world. In some cases a government, an organization, a church, or other institutions, plan carefully steps to achieve a change in behavior of the people. Sometimes the planning and implementation of a major change is well documented, so behavior analysts can reconstitute behavior processes and describe events in behavior analytic terms. That kind of reconstitution was made by Machado \& Todorov (2008) regarding the behavior of pedestrians and drivers in Brasília, Brazil. Up to 1996 the crosswalk sign on streets was utterly ignored by drivers and pedestrians everywhere in Brazil. Since 1996 it is safe to use the crosswalks in Brasília, but only in Brasília; the rest of the country did not change. Cultural practices of drivers and pedestrians changed after a concerted effort involving government, the media, nongovernmental organizations, churches, schools, and civil associations in general. The campaign involved publicity of rules: the law supposed to control the use of crosswalks. It also involved modeling: both professional and amateur artists showed how to use the crosswalk, both in vivo and in schools. Finally, after three months of rules and modeling, pedestrians and drivers were exposed to the contingencies: fines for those misbehaving, with the media showing everyone else who was being fined.

The well coordinated actions of so many institutions were possible through the intervening role of the University of Brasília. A short term metacontingency was established during meetings of a forum, where representatives of all institutions voluntarily engaged in the campaign discussed and voted on actions that should be taken, and on the timing of those actions. Twelve years later the change in behavior of drivers and pedestrians in Brasília is maintained. The short 


\section{TODOROV}

term metacontingency was sufficient to establish control of the behavior of drivers by pedestrians approaching a crosswalk, and of pedestrians by cars approaching a crosswalk. The concept of metacontingency is not necessary to explain the interplay between drivers and pedestrians near a crosswalk, but it certainly was useful in understanding how this major change in cultural practices was accomplished and maintained in Brasília. The work of Machado \& Todorov (2008) offers the opportunity for a manual for the education of drivers and pedestrians in any city, written in behavior analytic terms describing the behavioral processes involved.

\section{REFERENCES}

Glenn, S. S. (1986). Metacontingencies in Walden Two. Behavior Analysis and Social Action, 5, 2-8.

Glenn, S. S. (1991). Contingencies and metacontingencies: Relations among behavioral, cultural, and biological evolution. In P. A. Lamal (Ed.), Behavioral analysis of societies and cultural practices (pp. 39-73). New York: Hemisphere.

Glenn, S. S. (2004). Individual behavior, culture, and social change. The Behavior Analyst, 27, 133-151.

Machado, V. L. S. \& Todorov, J. C. (2008). Alguns conceitos envolvidos na análise e compreensão dos fenômenos culturais. In Silva, W. C. M. P. (Ed.), Sobre comportamento e cognição: análise comportamental aplicada. Santo André, SP, Brazil: ESETec.

Malott, M. E., \& Glenn, S. S. (2006). Targets of intervention in cultural and behavioral change. Behavior and Social Issues, 15, 31-56. http://dx.doi.org/10.5210/bsi.v15i1.344

Silva, A. V. \& Todorov, J. C. (2008). Evolução de práticas culturais. Brazilian Journal of Behavior Analysis, 4 (in press).

Skinner, B. F. (1953). Science and human behavior. New York, NY: McMillan.

Todorov, J. C. (1987). A Constituição como metacontingência. Psicologia: Ciência e Profissão, 7, 9-13.

Todorov, J. C. (2005). Laws and the complex control of behavior. Behavior and Social Issues, 14, 86-90.

Todorov, J. C., Moreira, M., Prudêncio, M. R. A., \& Pereira, G. C. C. (2004). O Estatuto da Criança e do Adolescente como metacontingência. Em M. Z. S. Brandão, F. C. S., Conte F. S., Brandão, Y. K. Ingberman, V. L. M. Silva, \& S. M. Oliani (Eds..), Sobre comportamento e cognição: contingências e metacontingências, contextos sócio-verbais e o comportamento do terapeuta (v. 13, pp. 44-51). Santo André, SP, Brazil: ESETec. 